\title{
Comentário
}

\section{A utilização do termo de compromisso de cessação de prática no combate aos cartéis}

Patrícia Regina Pinheiro Sampaio*

\section{Introdução}

O voto do conselheiro Luís Fernando Schuartz no Requerimento $\mathrm{n}^{\mathrm{o}}$ 08700.004221/2007-56, objeto deste comentário, constitui inegável marco na jurisprudência do Conselho Administrativo de Defesa Econômica (Cade), por refletir as razões que ensejaram a celebração do primeiro Termo de Compromisso de Cessação de Prática (TCC) relacionado a uma investigação de cartel realizada no Brasil.

Em breve síntese, e ressalvadas as nuances expostas neste artigo relativamente aos cartéis, os TCCs são acordos celebrados entre o Cade e uma ou mais pessoas investigadas por infração à ordem econômica, no qual, de um lado, os investigados se comprometem a fazer cessar a prática investigada e, de outro, a autoridade concorrencial suspende o processo administrativo com relação aos signatários do pacto que, uma vez cumprido, ensejará o arquivamento do processo.

Considerando que a higidez da ordem econômica constitui direito difuso, de que é titular toda a coletividade, ${ }^{1}$ a vantagem dos TCCs para a sociedade é a ime-

\footnotetext{
* Mestre e doutoranda pela Faculdade de Direito da Universidade de São Paulo (USP). Professora da FGV Direito Rio e advogada no Rio de Janeiro.

${ }^{1}$ Conforme o art. 1ํ, parágrafo único, da Lei no 8.884/94: “Art. 1ํ. Esta lei dispõe sobre a prevenção e a repressão às infrações contra a ordem econômica, orientada pelos ditames constitucionais de liberdade de iniciativa, livre concorrência, função social da propriedade, defesa dos consumidores e repressão ao abuso do poder econômico. Parágrafo único. A coletividade é a titular dos bens jurídicos protegidos por esta lei".
} 
diata cessação de uma prática que as autoridades de defesa da concorrência suspeitam acarretar efeitos anticompetitivos; para os investigados, o benefício reside em suspender o processo administrativo e, uma vez atestado o cumprimento do TCC, arquivá-lo sem condenação, de modo que, caso no futuro sejam investigados e condenados em outro processo administrativo, os signatários não serão considerados reincidentes. ${ }^{2}$

A atual legislação de defesa da concorrência impõe alguns requisitos adicionais para a celebração de TCCs com relação a cartéis, daí a relevância do voto do conselheiro Luís Fernando Schuartz proferido no julgamento do Requerimento n ${ }^{\mathrm{o}}$ 08700.004221/2007-56. ${ }^{3}$

\section{Breve histórico da disciplina legal dos TCCs em investigações de práticas infratoras da ordem econômica}

A possibilidade de celebração de TCCs encontra-se na Lei no 8.884 desde a sua promulgação, em 11 de junho de 1994.

Inicialmente, tratava-se de instrumento à disposição tanto do Cade quanto da Secretaria de Direito Econômico (SDE), nesse caso ad referendum do Cade, e não havia qualquer restrição legal quanto às práticas investigadas que poderiam, em tese, dar ensejo à celebração de TCCs. ${ }^{4}$

Com as alterações à Lei no $\times$ 8.884/94 promovidas pela Lei no $10.149 / 00$, tornouse vedada a celebração de TCC s com relação a cartéis. ${ }^{5}$

\footnotetext{
${ }^{2}$ Comentando o instituto à luz da redação original do art. 53 da Lei o 8.884/94, manifestou-se o exconselheiro do Cade, João Bosco Leopoldino da Fonseca: "A criação legal do 'compromisso de cessação' deixa no âmbito da incerteza a infringência contra a ordem econômica. Este compromisso se insere no instituto jurídico da transação. (...) As características da transação se evidenciam como um acordo, que se manifesta com o propósito de extinguir um litígio, em que existe uma reciprocidade de concessões e em que permanece inequívoca a incerteza quanto ao direito das partes. Na verdade, diferentemente do acordo no âmbito civil, aqui ocorre um acordo entre a autoridade encarregada de investigar e o representado cuja atividade econômica se analisa. Com esse acordo se extingue ou se paralisa a investigação, havendo reciprocidade de concessões: a autoridade não investiga mais e o representado paralisa a prática de atos que geraram suspeitas de infração contra a ordem econômica. O elemento da incerteza, de dúvida, está presente porque nem a autoridade nem o representado têm segurança sobre o desfecho da investigação, que poderia confirmar a existência da infração, mas poderia também afastar essa hipótese". FONSECA, João Bosco Leopoldino da. Lei de Proteção da Concorrência: comentários à legislação antitruste. 2. ed. Rio de Janeiro: Forense, 2001. p. 250-253.

${ }^{3}$ Requerimento realizado no curso do Processo Administrativo 08012.011142/2006-79, sendo requerente Lafarge Brasil S.A.

${ }^{4}$ Conforme redação original do caput do art. 53 da Lei no 8.884/94, posteriormente alterada: “Art.53. Em qualquer fase do processo administrativo poderá ser celebrado, pelo Cade ou pela SDE ad referendum do Cade, compromisso de cessação de prática sob investigação, que não importará confissão quanto a matérias de fato, nem reconhecimento de ilicitude da conduta analisada".

${ }^{5}$ Mediante o acréscimo do $\S 5^{\circ}$ ao art. 53 pela Lei no 10.149/00, que passou a dispor: “O disposto neste artigo não se aplica às infrações à ordem econômica relacionadas ou decorrentes das condutas previstas nos incisos I, II, III e VIII do art. 21 desta Lei". Esse dispositivo será novamente alterado, com a promulgação da Lei nō11.482/07.
} 
Essa vedação seria consequência da introdução, por esse diploma legal, do acordo de leniência no direito brasileiro, que deveria então ser o instrumento utilizado pelos investigados em casos de cartéis, caso desejassem pôr termo aos processos em curso sem condenação pela autoridade administrativa. ${ }^{6}$

Nos termos da legislação pátria, que segue, nesse tocante, a experiência internacional, ${ }^{7}$ a celebração de acordo de leniência depende da confissão da participação do signatário na conduta investigada e da sua colaboração efetiva para a produção de provas quanto à ocorrência da infração.

Compete à SDE, como principal órgão investigativo e instrutor dos processos administrativos em que se averigua a ocorrência de infrações à ordem econômica, celebrar os acordos de leniência quando presentes os requisitos da lei, cabendo ao Cade reconhecer se houve cumprimento do acordo pelos signatários e, nessa hipótese, decretar a extinção da ação punitiva da administração ou reduzi-la nos termos do art. 35-B da Lei no 8.884/94. ${ }^{8}$ Uma vez cumprido o acordo de leniência, os signatários podem vir a ter extinta a sua punibilidade nas esferas administrativa ${ }^{9}$ e penal, ${ }^{10}$ devendo-se

\footnotetext{
${ }^{6}$ A Lei no 10.149/00 acrescentou os arts. 35-B e 35-C à Lei no 8.884/94, que disciplinam a celebração de acordo de leniência no direito brasileiro.

${ }^{7}$ Para informações sobre o programa de leniência dos Estados Unidos, que possui previsões específicas para empresas e indivíduos, ver <www.usdoj.gov/atr/public/guidelines/0091.htm $>$ e $<$ www.usdoj. gov/atr/public/guidelines/0092.htm>. Acesso em: 20 fev. 2009. Para informações sobre o programa de leniência no âmbito da Comissão Européia, ver <http://ec.europa.eu/competition/cartels/legislation/ leniency_legislation.html>. Acesso em: 20 fev. 2009.

${ }^{8}$ Lei no 8.884/94. “Art. 35-B. A União, por intermédio da SDE, poderá celebrar acordo de leniência, com a extinção da ação punitiva da administração pública ou a redução de um a dois terços da penalidade aplicável, nos termos deste artigo, com pessoas físicas e jurídicas que forem autoras de infração à ordem econômica, desde que colaborem efetivamente com as investigações e o processo administrativo e que dessa colaboração resulte: I - a identificação dos demais coautores da infração; e II - a obtenção de informações e documentos que comprovem a infração noticiada ou sob investigação". As condições para celebração do acordo encontram-se no $\S 2$ o desse mesmo dispositivo: " $\S 2$ $\mathrm{O} O$ acordo de que trata o caput deste artigo somente poderá ser celebrado se preenchidos, cumulativamente, os seguintes requisitos: I - a empresa ou pessoa física seja a primeira a se qualificar com respeito à infração noticiada ou sob investigação; II - a empresa ou pessoa física cesse completamente seu envolvimento na infração noticiada ou sob investigação a partir da data de propositura do acordo; III - a SDE não disponha de provas suficientes para assegurar a condenação da empresa ou pessoa física quando da propositura do acordo; e IV - a empresa ou pessoa física confesse sua participação no ilícito e coopere plena e permanentemente com as investigações e o processo administrativo, comparecendo, sob suas expensas, sempre que solicitada, a todos os atos processuais, até seu encerramento".

${ }^{9}$ Art. 35-B, Lei no 8.884/94: § 4 $\mathrm{A}$ celebração de acordo de leniência não se sujeita à aprovação do Cade, competindo-lhe, no entanto, quando do julgamento do processo administrativo, verificado o cumprimento do acordo: I - decretar a extinção da ação punitiva da administração pública em favor do infrator, nas hipóteses em que a proposta de acordo tiver sido apresentada à SDE sem que essa tivesse conhecimento prévio da infração noticiada; ou II - nas demais hipóteses, reduzir de um a dois terços as penas aplicáveis, observado o disposto no art. 27 desta Lei, devendo ainda considerar na gradação da pena a efetividade da colaboração prestada e a boa-fé do infrator no cumprimento do acordo de leniência. $\S 5 \mathrm{~N}$ Na hipótese do inciso II do parágrafo anterior, a pena sobre a qual incidirá o fator redutor não será superior à menor das penas aplicadas aos demais coautores da infração, relativamente aos percentuais fixados para a aplicação das multas de que trata o art. 23 desta Lei.

${ }^{10} \mathrm{O}$ art. 35-C, da Lei $\mathrm{n}^{\circ}$ 8.884/94, determina que "nos crimes contra a ordem econômica, tipificados na Lei no 8.137, de 27 de novembro de 1990, a celebração de acordo de leniência, nos termos desta Lei, de-
} 
lembrar que cartéis, além de infrações administrativas, constituem crimes contra a ordem econômica, a teor da Lei nº 8.137/90. Trata-se, assim, de uma espécie de "delação premiada", já que o signatário confessa a sua participação e ajuda na coleta de provas para condenação de seus antigos parceiros na conduta anticompetitiva.

Assim, a partir da promulgação da Lei no $10.149 / 00$ e até a edição da Lei $\mathrm{n}^{\mathrm{o}}$ 11.482, em 31 de maio de 2007, esteve vedada a celebração de TCCs com relação à prática de cartel, devendo aqueles que desejassem pôr termo a uma investigação envolvendo acusação dessa espécie de conduta candidatarem-se, quando preenchessem os requisitos legais, à celebração de acordo de leniência.

Entretanto, com a nova redação trazida pela Lei no $11.482 / 07$ ao art. 53 da Lei no 8.884/94, os TCCs voltaram a ser permitidos no curso de investigações relacionadas a suspeitas de prática de cartéis, sujeitos, nesses casos, a alguns requisitos específicos.

\section{A celebração de TCCs com relação a cartéis}

Em primeiro lugar, cumpre esclarecer que, com a promulgação da Lei no 11.482/07, retirou-se a possibilidade de celebração de TCCs pela SDE ad referendum do Cade, de modo que, atualmente, somente o conselho pode celebrar TCCs. ${ }^{11}$

Para a celebração de TCCs em investigações de cartéis, o compromissário deve se comprometer a cessar a prática investigada e seus efeitos lesivos, devendo ser fixada multa por descumprimento das obrigações assumidas (art. 53, I e II, Lei no 8.884/94). Essa previsão já era encontrada na disciplina original dos TCCs.

A principal inovação trazida pela Lei no 11.482/07 reside em que, adicionalmente a esses requisitos, para que seja possível a celebração de TCCs com relação

\footnotetext{
termina a suspensão do curso do prazo prescricional e impede o oferecimento da denúncia. Parágrafo único. Cumprido o acordo de leniência pelo agente, extingue-se automaticamente a punibilidade dos crimes a que se refere o caput deste artigo".

${ }^{11}$ A SDE pleiteia algum grau de participação nesse processo, por ser o principal órgão de instrução de processos administrativos no âmbito do Sistema Brasileiro de Defesa da Concorrência. Em sugestões encaminhadas à consulta pública aberta pelo Cade para regulamentação do procedimento de negociação de TCCs, a SDE sugere que "de modo a reduzir importantes custos de transação e assimetria de informações, a SDE entende que no caso das propostas de TCCs apresentadas enquanto a averiguação preliminar ou processo administrativo ainda se encontrem em instrução nesta Secretaria, a negociação dever-se-ia dar junto à SDE, que apresentaria proposta final ao Plenário do Cade para aprovação ou rejeição. Tais propostas apresentam dificuldades consideráveis ao negociador do Conselho, uma vez que o negociador não possui, naquele momento, todos os dados e elementos necessários para avaliar a conveniência e oportunidade de se celebrar um acordo com a empresa ou pessoa física uma vez que o caso ainda não chegou ao Cade. $O$ fator-chave para a determinação do valor e outras variáveis de um acordo é a informação e a assimetria causada pelo fato da investigação se encontrar na SDE coloca o negociador do Conselho em posição desfavorável" (Ofício 7976/2008/SDE. Disponível em <www. mj.gov.br/sde>. Acesso em: 3 fev. 2009.
} 


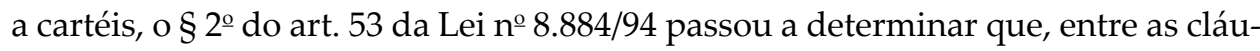
sulas a serem pactuadas com o compromissário, conste necessariamente "a obrigação de recolher ao Fundo de Defesa de Direitos Difusos um valor pecuniário", que não poderá ser inferior à multa administrativa mínima prevista no art. 23, I, da Lei Antitruste. ${ }^{12}$ Assim, em caso de investigação de cartéis, a celebração do TCC estará sempre condicionada ao depósito de um valor, em dinheiro, em benefício do Fundo de Defesa dos Direitos Difusos.

Um tema que despertou controvérsia no curso da negociação do TCC no caso cuja decisão será transcrita consistiu na necessidade ou não de confissão, por parte da empresa compromissária, quanto à sua participação na conduta investigada, assim como quanto à necessidade ou não de se obter o comprometimento de sua cooperação para a produção de provas contra as demais pessoas investigadas no processo.

Como visto, esses são elementos necessários à celebração de acordos de leniência, mas não são requisitos previstos no art. 53 da Lei no 8.884/94. Aliás, na redação original do art. 53, uma das características do TCC era justamente que sua celebração não implicava para o investigado a confissão quanto aos fatos investigados. ${ }^{13}$

Cumpre lembrar que no momento em que a Lei no 8.884/94 foi promulgada ainda não havia se introduzido em nosso ordenamento o acordo de leniência, que somente veio a ser positivado no final do ano 2000, com a promulgação da Lei no 10.149 .

Provavelmente por essa razão, ao disciplinar normativamente os procedimentos para celebração de TCC em seu regimento interno após o advento da Lei no 11.482/07, , ${ }^{14}$ o Cade introduziu o art. 129-G, que determina que, nos casos em que houver sido celebrado acordo de leniência pela SDE, o TCC deverá necessariamente conter reconhecimento de culpa por parte do compromissário. Nas demais hipóteses, será discricionária do Cade a decisão quanto a exigir ou não a confissão de participação na conduta investigada como condição para celebração do compromisso. ${ }^{15}$

\footnotetext{
${ }^{12}$ Art. 53. § 2o Tratando-se da investigação da prática de infração relacionada ou decorrente das condutas previstas nos incisos I, II, III ou VIII do caput do art. 21 desta Lei, entre as obrigações a que se refere o inciso I do $\S 1$ o deste artigo figurará, necessariamente, a obrigação de recolher ao Fundo de Defesa de Direitos Difusos um valor pecuniário que não poderá ser inferior ao mínimo previsto no art. 23 desta Lei.

${ }^{13}$ Atualmente, o regimento interno do Cade prevê a exigência de confissão de culpa como condição para a celebração de TCC em algumas situações, conforme se exporá adiante.

${ }^{14}$ Resolução Cade no ${ }^{2} 5 / 07$, conforme alterada.

${ }^{15}$ Art. 129-G, introduzido pela Res. Cade no 46/07: Nos casos em que houver sido celebrado acordo de leniência pela SDE, o compromisso de cessação deverá necessariamente conter reconhecimento de culpa por parte do compromissário. Nos demais casos, a exigência da confissão de culpa ficará a critério do Cade.
} 


\section{O voto condutor da celebração do TCC no caso em análise}

O voto cuja leitura se seguirá foi proferido em resposta a pedido formulado pela empresa Lafarge S.A. de celebração de TCC em investigação relacionada à possível existência de um cartel nos mercados de cimento e concreto.

Conforme se extrai do voto proferido pelo conselheiro Luís Fernando Schuartz em resposta ao requerimento de celebração de TCC formulado pela empresa Lafarge, a maior preocupação residiu em demonstrar que sua assinatura era "conveniente e oportuna" para a administração pública. ${ }^{16}$

Para esse fim, o conselheiro adotou o teste segundo o qual tal decisão seria conveniente e oportuna "se e somente se as consequências esperadas a ela associadas forem, desse ponto de vista exclusivamente, 'estritamente preferíveis' àquelas associadas à decisão de não celebrá-lo" ${ }^{17} \mathrm{Ou}$ seja, em sua decisão, o Plenário do Cade deveria responder à seguinte pergunta: "celebrar o TCC tal como proposto (de acordo com a minuta final apresentada) é preferível a não celebrar o TCC tal como proposto, vale dizer, a continuar litigando contra a proponente até um julgamento definitivo por parte do Poder Judiciário" ${ }^{18}$

Com esse questionamento, o conselheiro esclarece que a comparação a ser efetuada pelo Cade, ao decidir sobre a celebração do TCC, não deve ser com um eventual "TCC ideal” na visão de qualquer dos julgadores, mas sim entre as duas opções objetivamente apresentadas ao conselho, e que consistiam unicamente em aceitar ou não a versão da última minuta negociada.

Em seguida, o conselheiro apresenta as razões pelas quais entende que, no caso concreto, dever-se-ia responder afirmativamente à questão, no sentido de que celebrar o TCC se mostrava uma solução qualitativamente superior, em termos de atendimento ao interesse público, quando comparada à continuidade do processo administrativo, com relação à parte que requereu o TCC.

\footnotetext{
${ }^{16}$ A doutrina corrobora o entendimento de que a celebração de TCCs, até mesmo por sua complexidade técnica, não possa ser caracterizado como um ato plenamente vinculado, de modo que há um espaço decisório do Cade na avaliação quanto à presença de interesse público suficiente a justificar a sua celebração (daí a referência, pelo conselheiro relator, aos clássicos elementos do ato discricionário - conveniência e oportunidade). Ressalta-se, entretanto, que sempre que as condições assim o indicarem, a decisão pela celebração do TCC deve ser preferida, conforme destaca Rodrigues: “Entendemos que há discricionariedade na apreciação da conveniência e da oportunidade quanto à celebração do compromisso. Cumpre ao órgão público adotar alguma medida de tutela do direito transindividual, entre elas a celebração do compromisso. Além disso, deve-se verificar qual a situação mais compatível com as especificidades do caso concreto. É óbvio que, se houver as condições para a celebração do compromisso, deve-se privilegiar essa forma de composição de conflito, e é dever dos órgãos públicos tentá-la de forma exaustiva". RODRIGUES, Geisa de Assis. Breves considerações sobre o compromisso de cessação de prática. In: ROCHA, João Carlos de Carvalho et al. (Coord.). Lei Antitruste: 10 anos de combate ao abuso do poder econômico. Belo Horizonte: Del Rey, 2005. p. 124.

${ }^{17}$ Voto do conselheiro Luís Fernando Schuartz, p. 2-3.

${ }^{18}$ Voto do conselheiro Luís Fernando Schuartz, p. 3.
} 
Essa conclusão foi obtida a partir de uma comparação da solução trazida pela minuta de TCC negociada com o provável resultado final do processo administrativo relativamente à representada. Esse resultado foi construído utilizando-se o critério do "cálculo do valor presente da sanção esperada - VPSE", sendo a "sanção esperada" definida como "igual ao somatório das sanções em princípio mais prováveis para o tipo da conduta, multiplicadas pela probabilidade da sua aplicação à representada proponente do acordo, dado o conjunto probatório disponível com relação à mesma". ${ }^{19}$

O voto então traz a valor presente a sanção que se poderia esperar ser imposta à Lafarge ao final do processo administrativo e, eventualmente do processo judicial - dada a constância com que as decisões condenatórias do Cade são objeto de contestação no Judiciário pelas partes condenadas.

Dessa forma, entre outros elementos, o conselheiro demonstra matematicamente que, no caso em questão, a celebração do TCC representa uma solução superior para a administração pública, considerando: (i) a probabilidade de condenação pelo Cade: caso não fosse celebrado o TCC, o processo retomaria seu curso, e a hipótese de arquivamento dos autos sem condenação passaria a ser uma variável possível (por falta de provas quanto à ocorrência do ilícito ou participação da empresa, por exemplo); (ii) o tempo decorrente até a decisão final do Cade, considerando a média histórica de casos semelhantes; (iii) a probabilidade de que, em caso de condenação, a parte recorra ao Poder Judiciário e consiga suspender a multa, retardando a efetividade da decisão; (iv) o valor da contribuição pecuniária que a requerente do TCC se compromete a recolher voluntariamente ao Fundo de Defesa dos Direitos Difusos em face do histórico das multas impostas pelo Cade e a probabilidade de condenação.

\section{A necessidade ou não de confissão quanto à conduta investigada como condição para celebração do TCC no caso concreto}

Um dos pontos mais polêmicos relacionados à celebração do TCC no caso concreto residiu em se o Cade deveria ou não exigir a confissão da participação da compromissária na prática investigada como condição para a celebração do acordo. Conforme relatou o conselheiro Luís Fernando Schuartz, a proponente do TCC negara-se explicitamente a tal confissão. ${ }^{20}$

Sobre a questão, a SDE sustentou, em parecer de 26 de novembro de 2007, que

\footnotetext{
${ }^{19}$ Voto do conselheiro Luís Fernando Schuartz, p. 3.

${ }^{20}$ Conforme voto do conselheiro Luís Fernando Schuartz, p. 8.
} 
são inegáveis os benefícios para a administração pública e a sociedade da implementação de um mecanismo de negociação de acordos para encerramento de investigações de cartéis, desde que seja cumprido seu objetivo elementar de dissuadir futuras práticas lesivas à concorrência e não criar obstáculos à persecução criminal e ações privadas de indenização por danos causados por cartéis. Isso geralmente ocorre quando para se firmar o acordo se exige confissão de culpa, cooperação ativa e pagamento de contribuição pecuniária por parte do investigado.

Para a SDE, os TCCs em casos de cartéis têm por finalidade principalmente alcançar as empresas que não se qualificaram para um programa de leniência. ${ }^{21}$

Aduzindo ainda as peculiaridades da investigação realizada e o fato da compromissária já ter sido condenada no passado por infração da ordem econômica, a SDE defendeu que para que um acordo aderente ao interesse público fosse realizado dever-se-ia exigir

(i) confissão de culpa; (ii) reconhecimento da legalidade da busca;,22 (iii) obrigação de cooperação ativa na investigação; (iv) contribuição pecuniária em valor que garanta efeitos dissuasórios; e (v) não criação de obstáculos à persecução criminal e ações privadas de dano.

No entender da SDE, na minuta de TCC que estava sendo discutida, observava-se a presença dos itens "iv" $\mathrm{e}$ " $\mathrm{v}$ " acima mencionados, restando ausentes os demais. $^{23}$

Além da SDE, também o Ministério Público Federal posicionou-se contrariamente à celebração do TCC, por entender que deveria ter sido exigida da compromissária cooperação na investigação contra as demais empresas representadas no processo. ${ }^{24}$

\footnotetext{
${ }^{21}$ Nesse sentido, observou a SDE em sua manifestação: “O primeiro benefício de um termo de compromisso é obter a cooperação ativa de outros eventuais membros do cartel que não foram habilitados para o Programa de Leniência. Tal cooperação é de extrema importância para as autoridades, uma vez que torna mais céleres, eficientes e precisas as investigações".

${ }_{22}$ Trata-se de referência à busca e apreensão que havia sido efetuada no curso das investigações promovidas pela SDE.

${ }^{23}$ As premissas para a conclusão da SDE foram relatadas da seguinte forma: "a SDE considera que nesse processo - em que (i) há notícias de um cartel no setor há quase 55 anos; (ii) o SBDC investiga a prática há 10 anos; (iii) foram realizadas as buscas e apreensões mencionadas; (iv) há demanda da sociedade por resposta eficaz que pacifique o setor; (v) com o resultado das decisões judiciais a SDE já tem acesso a quase todo o material apreendido nas buscas; e, especificamente sobre a representada; (vi) a Lafarge Brasil S.A. é a mesma pessoa jurídica condenada, em 2005 no Processo Administrativo no ${ }^{\circ}$ 08012.002127/2002-14 ("Cartel das Britas"), a pagar multa recorde de $20 \%$ do seu faturamento bruto; e (vii) o Grupo Lafarge foi condenado em, ao menos, três jurisdições avançadas no combate aos cartéis".

${ }^{24}$ Conforme notícia intitulada "MPF discorda de termo de compromisso assinado pelo Cade", colhida em <http://noticias.pgr.mpf.gov.br/noticias-do-site/consumidor-e-ordem-economica/mpf-critica-acor-
} 
No entanto, a exigência de culpa como condição para celebração do TCC no caso concreto acabou não prevalecendo no Cade. Considerando que se tratava do primeiro TCC celebrado em relação a cartéis - não havia uma massa histórica crítica para constituir um viés de interpretação seguro quanto a ser ou não a confissão de participação na conduta investigada relevante em termos de estímulo à celebração de acordos de leniência ou não no futuro; e que, no processo em questão, não havia sido celebrado acordo de leniência - levaram o conselheiro a entender ser dispensável tal exigência no caso concreto. ${ }^{25}$

\section{Conclusão: da decisão no caso concreto e dos TCCs que a sucederam em investigações por prática de cartel}

O voto condutor do conselheiro Luís Schuartz veio a ser aprovado pelo Plenário do Cade, por maioria, ${ }^{26}$ em 28 de novembro de 2007, em decisão que teve a seguinte ementa:

Termo de cessação de conduta celebrado entre a empresa Lafarge Brasil S.A. e o Cade. Suspensão do processo administrativo ainda em trâmite perante a SDE, com relação à Lafarge. Obrigação por parte da compromissária de fazer cessar a prática e seus efeitos lesivos, bem como de adotar um programa de prevenção de infrações à ordem econômica. Pagamento de contribuição

do-assinado-pelo-cade/>, acesso em: 15 fev. 2009, da qual se extrai o seguinte trecho: “O Conselho Administrativo de Defesa Econômica (Cade) assinou ontem, 28 de novembro, um acordo com a empresa Lafarge Brasil S.A., acusada da prática de cartel - o primeiro ajuste desse tipo no país. O termo de compromisso de cessação de prática (TCC) prevê que a produtora do Cimento Mauá pague R\$ 43 milhões ao Fundo dos Direitos Difusos, mas a quantia não tem natureza de multa ou qualquer tipo de sanção. O ajuste também não implica reconhecimento das irregularidades. O Ministério Público Federal (MPF) foi contra o TCC e manifestou sua posição ontem durante sessão do Conselho. Para o representante do MPF no Cade, procurador regional da República, José Elaeres Teixeira, para que qualquer acordo em processo de cartel seja 'viável', ou seja, não atenda somente a interesses privados, a empresa acusada deve comprometer-se a colaborar com as investigações e o processo administrativo. 'No caso, o que se vê é que a empresa não só não se compromete a colaborar efetivamente com as investigações, como teve a preocupação em não emitir juízo de valor sobre documentos e tudo mais que existe no processo administrativo', alertou o procurador".

25 "Nesse sentido, acredito que as eventuais preocupações ante a perspectiva de um TCC sem confissão de culpa no caso da Lafarge sejam compreensíveis, mas inapropriadas. A decisão de fazer o TCC nesses termos não cria precedente para quem quer que seja, sendo completamente despropositada a reivindicação de 'tratamento igualitário' com respeito a seu conteúdo. Para o primeiro TCC (da história), a preocupação e a insistência estão fora de lugar, mesmo porque a confissão não virá em momento algum, inclusive no momento da eventual condenação. Negada a possibilidade da confissão pela proponente do TCC, a racionalidade da decisão do Plenário requer que o assunto seja posto de lado e se fixe o olhar, conforme exposto, nas consequências das decisões de autorizá-lo ou não. Já para os próximos da fila, os termos poderão ser radicalmente diferentes (...)". Voto, p. 7.

${ }^{26}$ Vencido o conselheiro Luiz Fernando Rigato Vasconcellos. 
pecuniária no valor de $\mathrm{R} \$ 43$ milhões a ser recolhida ao Fundo de Direitos Difusos.

Como visto, o Plenário não exigiu o reconhecimento da prática da conduta como condição para celebração do TCC.

Passado pouco mais de um ano da celebração do referido acordo, deve ser mencionado que já há casos na recente jurisprudência do Cade em que foram celebrados TCC com confissão de participação do compromissário na conduta investigada, ${ }^{27}$ bem como outros há em que, consideradas as peculiaridades concretas, a confissão foi dispensada. ${ }^{28}$

Um ponto bastante relevante nessa matéria reside em lembrar que a celebração de TCC não impede a persecução penal nas hipóteses de pessoas físicas investigadas por participação em cartéis. Assim, pelo menos nessas situações, o acordo de leniência segue como uma solução mais interessante para os investigados pessoas físicas, dada a possibilidade de extinção da punibilidade também na esfera penal, além, logicamente, de que, uma vez cumprido o acordo de leniência, a punibilidade pode vir a ser extinta na esfera administrativa, de modo que não haveria uma despesa pecuniária ao signatário do acordo de leniência. Igualmente para as pessoas jurídicas, o acordo de leniência pode levar à extinção da punibilidade na esfera administrativa, de modo que, cumpridas as exigências da lei, quando for o caso, a pessoa jurídica não terá que desembolsar recursos nem em pagamento de

\footnotetext{
${ }^{27}$ No caso em que se investigava suposta prática de cartel no mercado de mangueiras marítimas, a Bridgestone reconheceu sua participação na conduta como condição para que fosse celebrado o TCC, tendo em vista que anteriormente já havia sido celebrado acordo de leniência no curso da investigação. O voto do conselheiro Fernando de Magalhães Furlan que guiou a aprovação, pelo Plenário, da celebração do TCC, restou assim ementado: "Termo de Compromisso de Cessação de Prática celebrado entre a Birdgestone Corporation e o Cade. Suspensão do processo administrativo ainda em trâmite perante a SDE com relação à Bridgestone. Admissão de participação na conduta tendo em vista existência de Acordo de Leniência. Obrigação de colaboração com as investigações. Pagamento de contribuição pecuniária no valor de $\mathrm{R} \$ 1,594$ milhão a ser recolhida ao Fundo de Direitos Difusos. Oportunidade e conveniência. Aprovação da proposta" (voto proferido em 27 de agosto de 2008 e acompanhado à unanimidade pelos demais conselheiros).

${ }^{28}$ No caso envolvendo suposta prática de cartel por frigoríficos na compra de gado bovino, foi celebrado um TCC entre o Cade e uma empresa e duas pessoas físicas, no qual foi igualmente dispensada a confissão de participação na conduta investigada, ante a ausência de prévia celebração de acordo de leniência (PA 08012.002493/2005-16, decisão de 28 novembro de 2007). Interessante mencionar que esses TCCs foram firmados na mesma data daquela que é objeto do presente artigo (Lafarge). No caso Alcan, por maioria, foi decidida a celebração de TCC sem a exigência de reconhecimento de participação na conduta investigada, como se denota do voto condutor do conselheiro Ricardo Villas Bôas Cueva: "Não se pode esquecer que, no caso, a proposta de TCC foi apresentada antes mesmo que se abrisse prazo para defesa, ou seja, logo após instaurado o processo administrativo, o que certamente torna ainda mais significativa a aludida redução de custos sociais a ser atingida com o compromisso. Quanto à ausência de reconhecimento de culpa, nada há na lei que a imponha, sendo certo que, mesmo a norma infralegal editada pelo Cade apenas a exige se houver sido celebrado acordo de leniência, o que não é o caso" (voto no Requerimento 08700.5281/2007-96, referente ao PA 08012.004674/2006-50, apresentado em 23 de julho de 2008).
} 
multa administrativa nem em recolhimento de retribuição pecuniária ao Fundo de Defesa de Direitos Difusos, requisito essencial à celebração de TCCs com relação aos cartéis.

Verifica-se, assim, a complementaridade e utilidade de ambos os institutos pelas autoridades brasileiras.

\section{Ministério da Justiça \\ Conselho Administrativo de Defesa Econômica - Cade}

\section{Requerimento $\mathbf{n}^{\mathrm{o}}$ 08700.004221/2007-56 (referente ao Processo Administrativo no 08012.011142/2006-79}

Requerente: Lafarge Brasil S.A.

Advogados: Carlos Francisco de Magalhães, Gabriel Nogueira Dias, Maria da Graça Souza Britto e outros.

Relator: Conselheiro Luís Fernando Schuartz

\section{vOTO}

\section{Do requerimento}

1. Trata-se de requerimento protocolado em 6 de setembro de 2007, pela empresa Lafarge Brasil S.A. ("Lafarge"), integrante do polo passivo no Processo Administrativo no 08012.011142/2006-79, ainda em trâmite perante a Secretaria de Direito Econômico, no qual solicita o recebimento de sua proposta para celebração de termo de cessação de conduta ("TCC") nos autos do processo administrativo referido, nos termos no art. 53 da Lei no 8.884/94, com as alterações trazidas pela Lei $\mathrm{n}$-11.482/07. A proposta apresentada cumpre o disposto no art. 129-A do Regimento Interno do Cade, com a nova redação dada pela Resolução do Cade $n^{0}$ 46, de 6 de setembro de 2007, tendo sido deferido, a requerimento da proponente, tratamento confidencial aos termos da proposta e aos seus elementos durante a fase de negociação do compromisso. 
2. O processo em questão foi instaurado em desfavor de uma série de empresas do setor de cimento do Brasil, entre elas a Lafarge, objetivando apurar a ocorrência de infrações à ordem econômica, especialmente nos mercados de cimento e de concreto, supostamente cometidas pelas representadas e enquadráveis no art. 20 c/c art. 21, incisos I, II, III, IV e VIII, da Lei $\mathrm{n}^{\mathrm{o}} 8.884 / 94$.

3. Em 14 de setembro de 2007, por meio do Despacho no 7/LFS/2007, declarei aberto o prazo de 30 dias para negociação dos termos do TCC. O prazo foi prorrogado por mais 30 dias pelo Despacho $n^{-0} 7 / \mathrm{LFS} / 2007$. Após a realização de uma série de reuniões com representantes da requerente e membros do Cade a proposta inicial apresentada evoluiu para a minuta anexada ao presente despacho, sobre a qual apresento as seguintes considerações.

\section{Considerações sobre a minuta final do TCC}

\section{II.7 Legalidade}

4. A proposta de TCC satisfaz todos os critérios de legalidade previstos na legislação aplicável, dado que:

(i) não foi celebrado, no âmbito do presente processo administrativo, acordo de leniência que exigisse reconhecimento de culpa da parte da compromissária;

(ii) a compromissária assumiu a obrigação de fazer cessar a prática e seus efeitos lesivos, bem como de adotar um programa de prevenção de infrações à ordem econômica, tendo apresentado uma cópia do mesmo juntamente com a proposta (Anexo II à minuta de TCC juntada a este despacho);

(iii) existe previsão de contribuição pecuniária a ser recolhida ao Fundo de Direitos Difusos, incluindo as condições de pagamento e a penalidade por mora ou inadimplência (Cláusula 3.3. e Anexo I à minuta do TCC juntada);

(iv) existe previsão de multa para o descumprimento, total ou parcial, das obrigações assumidas no âmbito do compromisso (cf. Cláusula 8a da minuta juntada); 
(v) o valor de $R \$ 43$ milhões para a contribuição pecuniária é superior ao mínimo legal previsto no art. 23 da Lei $\mathrm{n}^{\mathrm{o}}$ 8.884/94 (faturamento bruto da sociedade excluídos os impostos $=\mathrm{R} \$ 413.752 .000,00 ; 2^{29}$

(vi) a compromissária está fazendo uso da faculdade de propositura de um compromisso de cessação pela primeira vez no âmbito deste processo administrativo.

\section{II.2 Conveniência e oportunidade}

5. A análise da conveniência e oportunidade da proposta deve, a meu ver, ser realizada a partir de um critério "consequencialista" de decisão, i. e., da valoração das consequências associadas à decisão de celebrar o TCC e à decisão de não celebrar o TCC tal como este se apresenta, contando-se a decisão de celebrar o TCC como "conveniente e oportuna" do ponto de vista da administração pública se e somente se as consequências esperadas a ela associadas forem, desse ponto de vista exclusivamente,"estritamente preferíveis" àquelas associadas à decisão de não celebrá-lo.

6. É importante explicitar que a comparação adequada para fins do juízo de conveniência e oportunidade pelo Cade no presente caso é aquela entre as consequências associadas a somente duas alternativas de decisão ora colocadas diante do Plenário, a saber, a decisão de celebrar o TCC nos termos constantes da minuta final, e a decisão de não celebrar o TCC, ou seja, de litigar administrativa e judicialmente contra a proponente até a decisão definitiva sobre o caso. Com efeito, dado que a propositura de um TCC por parte de uma representada em um processo administrativo só pode ser realizada uma única vez e que o conjunto de alternativas posto diante do Plenário compõe-se de somente dois elementos (aceitar a proposta nos seus termos, não aceitar a proposta nos seus termos), seria não somente irracional, mas também contrário aos interesses da administração, rejeitar-se a proposta sob o argumento de que haveria outra proposta que lhe seria preferível, pois esta simplesmente não seria uma opção factível para a administração. É verdade que restaria ainda a alternativa abstrata de uma futura transação judicial supondo a prévia condenação administrativa. Contudo, como mostrarei adiante, o critério sugerido para a construção de uma ordem de preferências sobre o conjunto das consequências associadas às decisões de celebrar ou não um TCC está sendo definido de forma a tornar, para a administração os benefícios associados a uma hipotética

${ }^{29}$ Cf. faturamento acostado às fls. 59-62 dos autos do requerimento. 
escolha por litigar administrativamente, para então transigir judicialmente, suficientemente próximos aos benefícios associados à escolha por celebrar o TCC

7. A conclusão pela conveniência e oportunidade da decisão de celebrar o TCC no caso concreto não decorre, portanto, de uma comparação hipotética entre a minuta colocada à deliberação do Plenário e uma minuta presumivelmente ideal aos olhos de quem quer que seja. Ao invés disso, ela decorre de uma resposta afirmativa à seguinte questão: celebrar o TCC tal como proposto é preferível a não celebrar o TCC tal como proposto, vale dizer, a continuar litigando contra a proponente até um julgamento definitivo por parte do Poder Judiciário? O critério empregado na análise que conduziu a essa resposta afirmativa está centrado no cálculo do valor presente da sanção esperada - VPSE, cujo significado vem explicado a seguir.

8. A sanção esperada associada a uma conduta em investigação no âmbito do SBDC é, no presente contexto, definida como igual ao somatório das sanções em princípio mais prováveis para o tipo da conduta, multiplicadas pela probabilidade da sua aplicação à representada proponente do acordo, dado o conjunto probatório disponível com relação à mesma. Note-se que o cálculo da sanção esperada tal como definida envolve o recurso a "probabilidades" em dois momentos e sentidos distintos. Em um primeiro momento, tem-se a identificação das sanções "em princípio mais prováveis" para o tipo da conduta que está sendo investigada, que consiste na listagem de um pequeno conjunto de percentuais possíveis para a determinação da sanção pecuniária prevista no art. 23 da Lei no 8.884/94 em função da sua maior frequência nos casos passados similares mais recentes, por exemplo, os percentuais de $15 \%$ e $20 \%$ na hipótese de condenação, e $0 \%$ na de não condenação em cartéis hard core.

9. No cálculo do valor da sanção esperada, os referidos percentuais aparecem enquanto os "estados da natureza" que deverão ser, então, em um segundo momento, multiplicados por suas respectivas probabilidades de realização no caso concreto, dados os elementos de prova à disposição da autoridade decisória. Diferentemente das "probabilidades" que se encontram implícitas na determinação das sanções "em princípio mais prováveis" para o tipo de conduta sob investigação no processo, os juízos de probabilidade envolvidos neste segundo momento da análise mensuram as chances de aplicação de cada uma das sanções relevantes. Para ficar no exemplo dos três estados da natureza correspondentes às sanções de $0 \%, 15 \%$ e $20 \%$, poder-se-ia pensar numa probabilidade de $20 \%$ de aplicação de uma sanção de $20 \% ; 60 \%$ de probabilidade de aplicação de uma sanção de $15 \%$; e, posto que a soma das probabilidades deve ser igual a um, 20\% de probabilidade de aplicação de uma "sanção" de $0 \%$ do faturamento bruto da empresa considerada. A sanção esperada, neste exemplo, seria igual a uma multa pecuniária de $20 \% .(0,2)+15 \% .(0,6)+0 \% .(0,2)=13 \%$ do referido faturamento bruto. Noutras palavras, a sanção esperada é a média ponderada das sanções percebidas, em abstrato, 
enquanto mais prováveis para a espécie de infração, com os pesos fornecidos pelas probabilidades de aplicação, em concreto, de cada uma dessas sanções.

10. Essas probabilidades de aplicação de cada uma das sanções tratadas como relevantes para a espécie de infração considerada referem-se à decisão final de mérito no âmbito do Poder Judiciário, pressupondo uma probabilidade de $100 \%$ de condenação pelo Cade e uma probabilidade de 100\% de recurso ao Judiciário pela parte após a condenação. Trata-se, portanto, das probabilidades condicionais de imposição de cada uma das sanções em questão pelo juiz, dadas as prévias condenações do Cade e proposição de ação judicial pela pessoa condenada. E essa dupla pressuposição que explica por que a decisão de fazer o TCC poderia ser vista, do ponto de vista dos benefícios da administração pública e em princípio, como suficientemente próxima à decisão de realizar a transação em juízo após a condenação administrativa - ainda que, como veremos, do ponto de vista dos custos da administração celebrar o TCC seja preferível a litigar para então transigir no Judiciário, e será tanto mais preferível quanto menor o tempo decorrido no processo até o momento da celebração do TCC.

11. As probabilidades utilizadas na segunda etapa do cálculo da sanção esperada não são "objetivas" no sentido de dizerem respeito a eventos aleatórios estruturalmente análogos ao lançamento de uma moeda ou o giro de uma roleta não viesadas, ou seja, eventos cujas frequências relativas permaneçam estáveis quando repetidas um número suficientemente elevado de vezes (as decisões judiciais de mérito em ações contra decisões condenatórias do Cade não são, em sentido técnico, interpretáveis como experimentos aleatórios bem-definidos). Por outro lado, elas tampouco são "subjetivas" no sentido de representarem os "graus de confiança" pessoais e idiossincráticos do indivíduo responsável pela decisão de aceitar ou não uma proposta inicial de compromisso, acerca das possibilidades de decisão colocadas posteriormente a um magistrado na hipótese de não aceitação e de condenação administrativa do proponente. Ainda que expressem, irremediavelmente, graus subjetivos de confiança na realização de eventos incertos, tais juízos de probabilidade contêm, como premissas de uma decisão da administração que deve poder prestar contas à coletividade quanto à sua adequação jurídica (mais precisamente, a sua conveniência e oportunidade), uma pretensão de objetividade, e devem basear-se na medida do possível em observações sobre fatos passados.

12. O cálculo da sanção esperada, contudo, é condição necessária mas insuficiente para a comparação entre as consequências associadas às decisões de celebrar ou não celebrar um TCC. Com efeito, a decisão final de mérito no âmbito do Poder Judiciário não somente é um evento incerto, mas é também um evento futuro. Se os benefícios associados a uma e outra alternativa de decisão devem ser efetivamente comparáveis, é necessário que sejam ambos trazidos ao mesmo instante do tempo através da aplicação de um fator de desconto que reflita a perda de 
valor das quantias monetárias pagas a título seja da sanção imposta pelo Cade, seja da contribuição pecuniária a recolher como consequência da celebração do TCC. A efetiva comparação entre os ganhos associados ao pagamento da contribuição pecuniária no presente e ao pagamento da multa no futuro requer, deste último, o cálculo do valor presente, i.e., o VPSE.

13. A planilha A anexa ao despacho apresenta, resumidamente, a estrutura do raciocínio envolvido no cálculo do VPSE em um caso genérico. Essa estrutura é uma simplificação, minimamente operacional para servir de diretriz em processos de aplicação do direito, de um complexo procedimento analítico que, na realidade, pode envolver um conjunto muito maior de variáveis capazes de influir sobre a definição dos estados da natureza relevantes e respectivas probabilidades. Por isso, ele não é um método que seja apresentado como "ótimo" em qualquer sentido. Entretanto - e para me valer da famosa expressão de Herbert Simon -, trata-se de um método "satisfatório" diante das informações disponíveis e do atual estágio do desenvolvimento institucional com respeito à negociação de TCCs com previsão de contribuição pecuniária. A pretensão é de que o método funcione como um standard inicial, ajustável dinamicamente à medida em que progridam o conhecimento e a experiência acumulados do Cade na direção da definição de "níveis de aspiração" mais ambiciosos.

14. O VPSE, apropriadamente calculado, deve servir como ponto focal para negociações de compromissos de cessação e avaliação de propostas levadas à deliberação do Plenário - sujeito a certas qualificações. O VPSE não deveria necessariamente ser tomado como o limite inferior do conjunto dos acordos convenientes e oportunos para a administração em um caso concreto. Em algumas situações tal limite estará abaixo do VPSE e em outras situações ele estará acima do VPSE. A posição do limite inferior do conjunto dos TCCs convenientes e oportunos para a administração pública com relação ao VPSE dependerá, essencialmente, de duas variáveis, a saber, (i) a magnitude e da economia de custos sociais viabilizada pela decisão de celebrar o TCC comparativamente à decisão de não celebrá-lo (incluindo principalmente, mas não apenas, os custos públicos incorridos até uma decisão final de mérito, mas também, os custos associados à alocação de recursos privados para a continuação do litígio e não para fins mais produtivos - supondo a mudança de padrão de comportamento concorrencial assumida como obrigação pela empresa ao fazer o TCC); e (ii) a magnitude das externalidades positivas geradas pela realização do TCC em termos: (a) do imediato desalinhamento de interesses que pode provocar entre a compromissária e as demais representadas no processo administrativo - supondo a preexistência do cartel; (b) das sinalizações positivas para todos os demais agentes econômicos que não são parte do processo quanto à eficácia no enforcement da legislação de defesa da concorrência; e (c) da desobstrução dos caminhos a percorrer por outros agentes públicos na persecução e punição dos demais membros do cartel e por agentes privados na reparação dos 
prejuízos sofridos em virtude do seu funcionamento. Quanto maiores essas duas magnitudes, maior poderá ser a diferença entre o VPSE e o valor da contribuição juridicamente justificável para a celebração do acordo.

15. Em propostas de TCCs que, como a atual: (i) não contêm reconhecimento de culpa ou renúncia a direito subjetivo em benefício de órgãos do SBDC, mas incluem programas estruturados e críveis de prevenção de infrações à ordem econômica (com regime de livre acesso), bem como alguma forma de cooperação com a SDE na prestação de informações que contribuam para o bom andamento da instrução com relação às demais representadas; (ii) a propositura do compromisso pela parte se dá logo após instaurado o processo; e (iii) o TCC é o primeiro a ser proposto, sua celebração deve, a meu ver, estar condicionada ao pagamento de um valor a título de contribuição pecuniária "suficientemente próximo" ao VPSE (obviamente, se está falando do limite inferior do "intervalo de conveniência", não do TCC de máximo benefício líquido para a administração se aceito pela contraparte). O motivo para não se exigir, neste caso, a igualdade entre valor da contribuição e VPSE está em que, presumivelmente, fazer o acordo nesses termos ainda seria preferível a continuar litigando, já que os benefícios sociais líquidos associados à primeira decisão ainda seriam aparentemente superiores aos benefícios sociais líquidos associados à segunda decisão: os benefícios seriam possivelmente próximos nesses dois casos, mas os custos seriam muito menores com o acordo.

16. A limitação no conjunto de alternativas de decisão para fins do juízo de conveniência e oportunidade em relação a uma proposta de TCC e o recurso a um ponto focal explícito como o VPSE garantem racionalidade à discussão e evitam as armadilhas conceituais e as tentativas estratégicas de manipulação que inevitavelmente ocorreriam se permitíssemos o contrabando de visões particulares sobre o interesse público para dentro do processo de decisão. Por exemplo, dado que a comparação adequada não é entre a decisão de fazer o TCC e a decisão de fazer o acordo "ótimo", mas entre a de fazer o TCC e a de litigar até a decisão final de mérito no âmbito do Poder Judiciário, pode-se recolocar sobre bases mais produtivas a difícil questão acerca da relevância da confissão de culpa enquanto condição para a celebração de um TCC.

17. Salvo nas hipóteses de preexistência de acordo de leniência, a lei atribuiu ao Cade a prerrogativa de decidir, discricionariamente, os casos em que a celebração do TCC será ou não condicionada ao reconhecimento de culpa por parte do proponente (art. 129-G da Resolução Cade no 46/2007). Quando a confissão de culpa do proponente é relevante a ponto de tornar a decisão de não realizar o TCC e prosseguir litigando até a decisão final de mérito estritamente preferível a celebrar o TCC (supondo uma contribuição pecuniária satisfatória)? A meu ver, não há ainda uma boa resposta genérica para essa pergunta, uma vez que ela só será trazida pela experiência com TCCs previamente feitos e observações dos seus impactos em termos da interação dinâmica entre o aumento esperado das multas impostas aos agentes 
que decidem não celebrá-los da forma desejada pela administração, e a propensão dos demais agentes a aceitar as condições exigidas pela mesma em futuras negociações.

18. À medida então que for se afirmando a maturidade institucional dos órgãos do SBDC e consolidando a confiança da coletividade no respeito às garantias e direitos de pessoas físicas e jurídicas que decidem oferecer sua colaboração às autoridades, o natural é surgir dessa interação dinâmica um círculo virtuoso no qual, ao aumento do número de TCCs, siga-se o aumento dos VPSEs; ao aumento dos VPSEs, siga-se o aumento da propensão dos agentes envolvidos em cartéis a fazer TCCs mais vantajosos para a administração e o aumento no número de TCCs mais severos, e assim por diante, até o ponto em que se generalize e se normalize a expectativa de que a exigência do reconhecimento de culpa be part of the deal (como parece ser o caso nas jurisdições mais desenvolvidas). No instante $t_{0}$ desse processo evolutivo, não obstante, minha impressão é que a insistência a priori no reconhecimento de culpa como condição para celebração de um TCC seja causa de mais males que benefícios.

19. Nesse sentido, acredito que as eventuais preocupações ante a perspectiva de um TCC sem confissão de culpa no caso da Lafarge sejam compreensíveis, mas inapropriadas. A decisão de fazer o TCC nesses termos não cria precedente para quem quer que seja, sendo completamente despropositada a reivindicação de "tratamento igualitário" com respeito a seu conteúdo. Para o primeiro TCC (da história), a preocupação e a insistência estão fora de lugar, mesmo porque a confissão não virá em momento algum, inclusive no momento da eventual condenação. Negada a possibilidade da confissão pelo proponente do TCC, a racionalidade da decisão do Plenário requer que o assunto seja posto de lado e se fixe o olhar, conforme exposto, nas consequências das decisões de autorizá-lo ou não. Já para os próximos da fila, os termos poderão ser radicalmente diferentes - sobretudo ao ter-se em conta que o consumo pelo Cade de produto idêntico no mesmo processo tem utilidade marginal decrescente e as consequências da opção pelo TCC incluem um tratamento mais gravoso para os que restam.

20. É importante deixar registrado que a recente legislação brasileira sugere a utilização de um escalonamento na fixação das contribuições, que favorece o primeiro proponente e desfavorece, em comparação ao tratamento a ele conferido, os seguintes, na sua ordem de chegada (cf. a respeito o art. 129-E da Resolução no 46/2007). Em outras palavras, está-se diante de um mecanismo capaz de compensar tratamentos eventualmente mais brandos (se comparados ao VPSE) com tratamentos eventualmente mais onerosos (se comparados ao mesmo valor), exigindo porventura, aí sim, a confissão de culpa, tendo sempre à vista o interesse da administração em poupar recursos escassos, focando-os na investigação e punição mais rigorosa das líderes do cartel, com respeito às quais possa valer realmente a pena litigar até o fim. 
21. O argumento que me levou a aceitar como satisfatórios os termos da minuta final de TCC, trazida à deliberação do Plenário enquanto Anexo I ao presente despacho, parte da recusa explícita de confissão de culpa por parte da proponente e se limita à apresentação das razões pelas quais a contribuição pecuniária, em conjunto com as demais obrigações previstas na minuta anexa, tornam a realização do TCC, tal como proposto, conveniente e oportuna da perspectiva do interesse público. Os detalhes do argumento vêm explicitados nos parágrafos subsequentes.

22. A demonstração de que o valor da contribuição pecuniária estabelecida na minuta de TCC está suficientemente próxima ao VPSE correspondente, no caso, à Lafarge (cf. item 15.), não consiste na "descoberta" do VPSE - ou do conjunto de VPSEs - supostamente correto. Ao invés disso, a prova procede indiretamente, partindo do valor da contribuição para o VPSE e não o inverso. A minuta de TCC prevê o pagamento de uma contribuição pecuniária de R \$ 43 milhões. Assumindose que uma contribuição pecuniária conveniente e oportuna da perspectiva da administração pública seja aquela de valor suficientemente próximo ao VPSE, e que referido atributo se verifica se e somente se tal valor é, no máximo, $10 \%$ inferior ao VPSE, segue-se logicamente que o valor da contribuição prevista será suficientemente próximo ao VPSE se e somente se o VPSE correspondente, neste processo, à Lafarge, for igual ou inferior a $\mathrm{R} \$ 47,300$ milhões. Caso contrário, a contribuição pecuniária terá sido insatisfatória, vale dizer, o seu valor não será suficientemente próximo ao VPSE relevante para o caso.

23. O método para verificação dessa condição necessária e suficiente, sem a pretensão da estimativa do "verdadeiro" VPSE para o caso, compõe-se de duas etapas. Na primeira, identifica-se o percentual que, multiplicado pelo faturamento bruto da Lafarge referente a 2006 - líquido de impostos e atualizado -, mais aproximaria $\mathrm{R} \$ 47,300$ milhões, enquanto valor presente de uma sanção a ser aplicada pelo Poder Judiciário em algum momento do futuro. Assumindo-se que esse momento do futuro ocorrerá após 42 meses de tramitação do processo administrativo e 84 meses de tramitação de um processo judicial, um cálculo simples (com o auxílio da planilha A exibida em anexo) mostra que o valor em questão é aproximadamente igual a $15,5 \%$, i.e., que o valor da contribuição definido no TCC seria suficientemente próximo ao valor presente de uma sanção de 15,5\% do faturamento da empresa, a pagar após 126 meses (com 100\% de certeza). A transição à segunda etapa dá-se com o enunciado da restrição $\mathrm{p}_{1} \mathrm{~s}_{1}+p_{2} \mathrm{~S}_{2}+\ldots+p_{n} \mathrm{~s}_{n} \leq 0,155\left(p_{i} \geq\right.$ $0, \forall_{i}^{\prime \prime} \in\{1, \ldots, \mathrm{n}\}, \sum_{i=1}^{n} p_{i}=1$, e $\left.0 \leq s_{i} \leq 0,3, \forall_{i} \in\{1, \ldots, \mathrm{n}\}\right)$ e, por fim, o teste numérico dessa desigualdade com relação a combinações juridicamente plausíveis de valores para as probabilidades (os $p^{\prime} s$ ) e sanções (os $s^{\prime} s$ ). Havendo uma amostra pequena mas razoável de combinações para as quais a desigualdade acima for satisfeita, minha 
sugestão é que se trate como aceitável a suposição de que o VPSE seja um dos elementos do conjunto de todas as combinações que satisfazem essa desigualdade, i.e., um elemento do conjunto de todos os pares $(\mathbf{p}, \mathbf{s})^{30}$ tais que $\sum_{i=1}^{n} p_{i} s_{i} \leq 0,155$.

24. Por exemplo, a condição enunciada no final do parágrafo precedente é satisfeita para a combinação (v. a respeito a primeira coluna da planilha B anexa ao presente despacho): ((10\%, 70\%, 20\%), (0\%, 15\%, 20$))$, i.e., a combinação na qual há $10 \%$ de probabilidade de não condenação pelo Judiciário; $70 \%$ de probabilidade de condenação a uma multa; de 15\% e 20\% de probabilidade de condenação a uma multa de $20 \%$ sobre o faturamento da empresa (atualizado até 2007 e excluídos os impostos). Outras combinações possíveis (v. as demais colunas da planilha B) são as seguintes: $((20 \%, 40 \%, 40 \%),(0 \%, 15 \%, 20 \%)),((20 \%, 50 \%$, $30 \%),(0 \%, 15 \%, 20 \%))$ e $(20 \%, 50 \%, 12 \%, 18 \%),(0 \%, 15 \%, 20 \%, 30 \%))$, a última, vale mencionar, com previsão para uma sanção pecuniária de $30 \%$ do faturamento com probabilidade de $18 \%$.

25. Note-se que o centro de gravidade das combinações apresentadas acima é dado pela multa de $15 \%$. É a ela que, de fato, atribui-se maior peso em todos os exemplos. Isso me pareceu bastante razoável em razão (i) do caráter problemático da afirmação da existência de reincidência neste caso; ${ }^{31}$ e (ii) da presença de circunstâncias possivelmente atenuantes, como a de se tratar de empresa não líder, de reduzida participação de mercado (em 2006, 6,24\%) e atuação geograficamente restrita (Minas Gerais e Rio de Janeiro, sem operações no estado de São Paulo).

26. Além disso, a suspensão do processo em relação à Lafarge de modo algum implicará prejuízo à continuidade das investigações da SDE com respeito às outras empresas representadas, estando a Secretaria liberada para a utilização dos documentos apreendidos na Lafarge nessas investigações assim que obtiver a autorização judicial, sem restrições à regra acerca da publicidade/confidencialidade de documentos constantes na Portaria SDE n⿳0 04. Quanto a esse ponto, deve-se dizer que uma minuta anterior proposta pela empresa continha previsão de disponibilização imediata de todos os documentos apreendidos no Rio de Janeiro e suspensão, até o cumprimento final do TCC, da ação judicial relativa à busca e apreensão dos mesmos, e que as cláusulas correspondentes foram retiradas por interesse do SBDC. Por último, não há qualquer razão para assumir que viria a

\footnotetext{
${ }^{30}$ Os elementos dos pares são vetores com $n$ coordenadas. Ilustrativamente, no primeiro exemplo abaixo, $\mathbf{p}=(10 \%, 70 \%, 20 \%)$ e s $=(0 \%, 15 \%, 20 \%)$.

${ }^{31}$ Apesar de condenada no processo administrativo relativo ao cartel das britas, não consta que a Lafarge tenha propriamente sido o agente infrator. Com efeito, sua participação no processo deu-se como herdeira de um passivo advindo da aquisição de duas das sociedades representadas, a saber, Britabrás e Khouri, as quais figuram no voto condutor do conselheiro-relator, Luiz Prado, como as responsáveis pelas condutas investigadas e punidas.
} 
ser descumprida a promessa da compromissária no âmbito do presente TCC no sentido de se comportar de acordo com a legislação de defesa da concorrência e competir efetivamente nos mercados nos quais atua. Essa tem sido, aparentemente, a posição adotada pela Lafarge em todas as demais jurisdições, e que está refletida, segundo declarações prestadas pelo presidente da companhia, nas medidas adotadas para a execução, em nível mundial, de seu programa de compliance. Sua relevância, para a ocorrência de alterações estruturais nesse preocupante setor, não se deve subestimar, assim como não há como subestimar a relevância do efeito sinalizador de uma decisão que implica pagamento, por uma representada em processo administrativo, de um valor histórico sob diversos aspectos - especialmente, como não se cansa de nos fazer lembrar o nosso procurador-geral ante a relativa inefetividade das decisões de imposição de multas por infrações à ordem econômica ${ }^{32}$ e à ampla ressonância que a veiculação imediata de notícias com sinal contrário pela imprensa pode provocar no interior da coletividade.

27. A propósito, tampouco deve ser subaproveitada a disposição da empresa em prestar cooperação às autoridades no âmbito das investigações relativas às demais representadas (cf. Cláusula 3.2. (ii)) A produtividade de qualquer relação de cooperação pressupõe os incentivos corretos de ambos os lados e um grau de confiança bilateral que, neste caso, só será plenamente atingido ao longo da interação. Dada a obrigação nesse sentido assumida pela compromissária, minha recomendação à SDE é que acione o canal de comunicação o mais brevemente possível.

28. Pelo exposto, considero oportuna e conveniente a minuta final de TCC, e recomendo a sua aprovação ao Plenário.

29. É a decisão, que submeto à apreciação e homologação do Plenário nos termos do art. 9º, incisos II e III, da Lei $\mathrm{n}^{\circ}$ 8.884/94.

A requerente deu-se por intimada da presente decisão nesta data.

Brasília, 28 de novembro de 2007

\section{LUÍS FERNANDO SCHUARTZ \\ Conselheiro-Relator}

\footnotetext{
32 Segundo o "Relatório de Gestão e Correição" (2006/07), apresentado pela Procuradoria do Cade em sessão pública, de 1994 a 2005 mais de $80 \%$ das condenações em processos administrativos não foram cumpridas. Ainda que a situação tenha melhorado no biênio indicado, uma comparação com os resultados nas jurisdições mais desenvolvidas revela que há um caminho a percorrer na direção de um enforcement plenamente eficaz da legislação.
} 